\title{
Tonicity-dependent induction of Sgk1 expression has a potential role in dehydration-induced natriuresis in rodents
}

\author{
Songcang Chen,, ${ }^{1}$ Christopher L. Grigsby, ${ }^{1}$ Christopher S. Law, ${ }^{1}$ Xiping Ni, ${ }^{2}$ Nada Nekrep, ${ }^{1}$ \\ Keith Olsen, ${ }^{1}$ Michael H. Humphreys, ${ }^{2}$ and David G. Gardner ${ }^{1,2}$
}

1Diabetes Center and ${ }^{2}$ Department of Medicine, UCSF, San Francisco, California, USA.

\begin{abstract}
In various mammalian species, including humans, water restriction leads to an acute increase in urinary sodium excretion. This process, known as dehydration natriuresis, helps prevent further accentuation of hypernatremia and the accompanying rise in extracellular tonicity. Serum- and glucocorticoid-inducible kinase (Sgk1), which is expressed in the renal medulla, is regulated by extracellular tonicity. However, the mechanism of its regulation and the physiological role of hypertonicity-induced SGK1 gene expression remain unclear. Here, we identified a tonicity-responsive enhancer (TonE) upstream of the rat $S g k 1$ transcriptional start site. The transcription factor NFAT5 associated with TonE in a tonicity-dependent fashion in cultured rat renal medullary cells, and selective blockade of NFAT5 activity resulted in suppression of the osmotic induction of the Sgk1 promoter. In vivo, water restriction of rats or mice led to increased urine osmolality, increased Sgk1 expression, increased expression of the type A natriuretic peptide receptor (NPR-A), and dehydration natriuresis. In cultured rat renal medullary cells, siRNA-mediated Sgk1 knockdown blocked the osmotic induction of natriuretic peptide receptor 1 (Npr1) gene expression. Furthermore, $\mathrm{Npr1}^{-/-}$mice were resistant to dehydration natriuresis, which suggests that Sgk1-dependent activation of the NPR-A pathway may contribute to this response. Collectively, these findings define a specific mechanistic pathway for the osmotic regulation of Sgk1 gene expression and suggest that Sgk1 may play an important role in promoting the physiological response of the kidney to elevations in extracellular tonicity.
\end{abstract}

\section{Introduction}

Persistent hypertonicity, typically reflecting a high extracellular sodium concentration, stresses mammalian cells due to the ensuing osmotic efflux of water that shrinks the cells and concentrates their contents. Under most conditions, the concentration of extracellular sodium in mammals is controlled primarily through regulation of water metabolism. As extracellular sodium and plasma tonicity rise, the thirst mechanism is activated, and secretion of the neurohypophyseal hormone vasopressin into plasma increases. Vasopressin binds to its cognate receptors in the collecting duct of the kidney, resulting in increased water retention.

Following short-term water restriction, several mammals demonstrate an acute increase in urinary sodium excretion that is independent of changes in water metabolism. This response, termed dehydration natriuresis (1-11), plays an important role in preventing further accentuation of hypernatremia and the accompanying rise in extracellular tonicity. A similar natriuresis is seen following infusion of hypertonic saline (12). Investigations to date have suggested a role for central versus peripheral osmoreceptors and blood-borne versus neural effectors in contributing to dehydration-induced natriuresis; however, the precise mechanism(s) underlying this natriuresis remains undefined.

Conflict of interest: The authors have declared that no conflict of interest exists. Nonstandard abbreviations used: $\alpha \mathrm{ENaC}, \alpha$ subunit of ENaC; $\mathrm{ANP}$, atrial natriuretic peptide; $\mathrm{ENaC}$, epithelial sodium channel; IMCD, inner medullary collecting duct; NFAT, nuclear factor of activated T cells; NPR-A, type A natriuretic peptide receptor; Sgk1, serum- and glucocorticoid-inducible kinase; TonE, tonicity-responsive enhancer; TonEBP, TonE-binding protein.

Citation for this article: J. Clin. Invest. 119:1647-1658 (2009). doi:10.1172/JCI35314
Changes in renal medullary tonicity have been shown to regulate the expression of a variety of genes, including those encoding aldose reductase (13), the betaine/GABA transporter (14), taurine transporter (TauT) (15), HSP-70 (16), the sodium/myo-inositol cotransporter (17), the urea transporters (18), and aquaporin 2 (19), expression of all of which increases in response to increased extracellular tonicity. In each case, the increase in gene expression has been traced to an increase in gene transcription that is mediated through a TonE (TGGAAANNNCN, where $\mathrm{N}$ is any nucleotide positioned in the promoter of the target gene) $(14,20)$. The TonE-binding protein (TonEBP) is a dimeric protein that associates with the TonE in asymmetric fashion, effectively encircling its recognition element in the target gene promoter (21). Dimerization is not tonicity dependent, but it is required for DNA binding and activation of the transcription factor (22). TonEBP has subsequently been identified as a distant relative of the nuclear factor of activated T cells (NFAT) nuclear transcription factor family (i.e., it shares $43 \%$ sequence identity with NFAT1) and assigned the name NFAT5 (23). In the basal state, TonEBP/NFAT5 is distributed in both the nucleus and cytoplasm of the cell. Following exposure to a hypertonic environment in vitro $(24,25)$ or water restriction in vivo (26), it translocates selectively into the nuclear compartment. Hypertonicity also increases NFAT5 gene expression, albeit with a delayed time course $(27,28)$.

Each of the NFAT5-mediated osmosensitive genes mentioned above, in one way or another, generates products or activates signaling pathways that function in a counterregulatory fashion to mitigate the impact of the hypertonic stimulus. Most of the changes are, in fact, passive adaptive reactions to protect cells from 
A

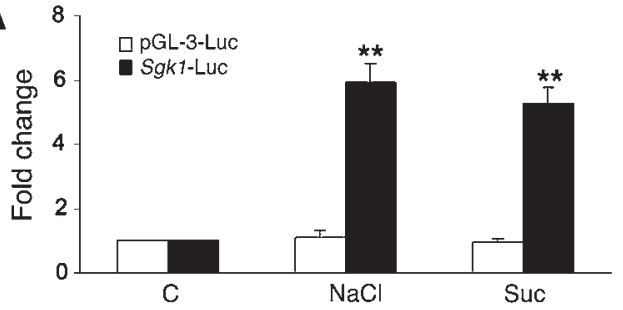

B

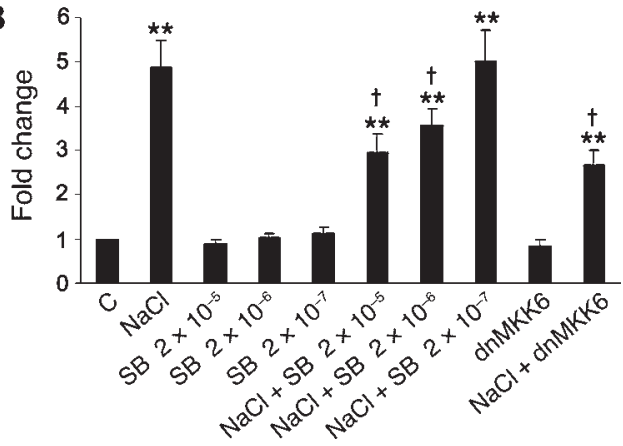

Figure 1

Osmotic induction of rat $S g k 1$ promoter in rat IMCD cells. (A) IMCD cells were cotransfected with $1 \mu \mathrm{g}$ of -1430 rat Sgk1-Luc (wild-type) and $0.2 \mu \mathrm{g}$ actin- $\beta$-galactosidase. Twenty-four hours later, they were treated with $75 \mathrm{mM} \mathrm{NaCl}$ or $150 \mathrm{mM}$ sucrose (Suc) for 24 hours. Cells were harvested, and luciferase levels were measured and normalized to $\beta$-galactosidase activity. C, control. (B) p38 MAPK inhibitor SB203580 (SB) and dominant negative MKK6 (dnMKK6) inhibit osmotic induction of the Sgk1 gene promoter in IMCD cells. The -1430 rat Sgk1-Luc reporter and actin- $\beta$-galactosidase were transfected into IMCD cells in the presence or absence of $0.2 \mu \mathrm{g}$ of a dominant negative mutant of MKK6. Twenty-four hours later, cells were incubated with $75 \mathrm{mM} \mathrm{NaCl}$ for 24 hours in the presence of different concentrations (M) of SB203580 (1 hour preincubation) as indicated. The pooled data are from 3-4 independent experiments. ${ }^{* \star} P<0.01$ versus control; t $P<0.05$ versus $\mathrm{NaCl}$ alone.

hypertonic damage. To date, few tonicity-induced genes that possess the capacity to reduce hypertonicity per se, and none linked to dehydration natriuresis, have been identified.

Serum- and glucocorticoid-regulated kinase 1 (Sgk1) is a signaling kinase that is induced by a variety of stimuli, including serum (29), glucocorticoids $(29,30)$, TGF- $\beta(31,32)$, aldosterone (33), and hypertonicity (34-38). The mechanism and the underlying physiological function of hypertonicity-induced SGK1 gene expression remain unclear. We have shown previously that Sgk1, which is avidly expressed in the renal medulla (39), is stimulated by increased extracellular tonicity in inner medullary collecting duct (IMCD) cells of the kidney (40). We have also demonstrated that hypertonicity increases expression of the type A natriuretic peptide receptor (NPR-A) (41), a guanylyl cyclase-linked receptor that binds both atrial natriuretic peptide (ANP) and the B-type natriuretic peptide (BNP), leading to an increase in renal excretion of sodium. Water deprivation leads to increased renal medullary sodium concentration $(4,42,43)$. We reasoned that tonicity-dependent stimulation of Sgk 1 and subsequent activation of NPR-A gene expression might be linked to the dehydration natriuresis described above.

In the present study, we demonstrate that Sgk1 does indeed serve as an intermediary in tonicity-dependent stimulation of
NPR-A gene expression and that dehydration-induced natriuresis is linked to increased expression of Sgk1 and NPR-A in rats and mice. Furthermore, dehydration-induced natriuresis does not occur in NPR-A gene-deleted ( $\left.\mathrm{Npr}^{-/-}\right)$mice. The osmotic induction of Sgk1 gene expression in IMCD cells is associated with an increase in Sgk1 gene promoter activity, and this induction is critically dependent upon a single TonE site positioned between -324 and $-312 \mathrm{bp}$ upstream from the transcription start site in the gene. Interaction of NFAT5 with this TonE site is required for the hypertonic, but not the hypotonic, induction of the Sgk1 gene promoter. Collectively, these data suggest a role for Sgk1 and the intrinsic renal natriuretic peptide system as contributors to the phenomenon of dehydration-induced natriuresis.

\section{Results}

Like the Sgk1 gene transcript and the Sgk1 protein (40), Sgk1 promoter activity proved to be very responsive to increases in extracellular tonicity in IMCD cells. As shown in Figure 1A, IMCD cells transfected with the Sgk promoter-driven luciferase reporter demonstrated a 5- to 6-fold increase in promoter activity following exposure to an approximately $150-\mathrm{mOsm} / \mathrm{kg}$ increase (i.e., above the tonicity of DMEM medium, which is $296 \mathrm{mOsm} / \mathrm{kg} \mathrm{H}_{2} \mathrm{O}$ ) in extracellular tonicity. The background vector (pGL3-Luc) showed no sensitivity to extracellular tonicity.

The osmotic activation of this promoter was dependent on the p38 MAPK signaling system (Figure 1B). Treatment of the IMCD cells with the p38 MAPK inhibitor SB203580 led to a dose-dependent suppression of the osmotic induction of Sgk1-Luc reporter activity. Similarly, cotransfection with a dominant negative mutant of MKK6, an activating kinase immediately upstream from p38 MAPK (41), resulted in a nearly 50\% decrease in the tonicity-dependent induction.

Earlier studies (34) indicated that osmotic induction of the Sgk1 promoter in NMuMg cells is dependent on a GC-rich region, shown in vitro to associate with the transcription factor Sp1, in close proximity to the transcription start site of the Sgk1 gene. Since Sp1-binding sites have not been linked to induction of osmotically sensitive genes in renal cells, we examined the promoter sequence for the presence of alternative sites that might contribute to the osmotic induction. We identified a consensus tonicity-responsive enhancer (TonE) (44) approximately $312 \mathrm{bp}$ upstream from the transcription start site. The rat Sgk1 TonE (TGGAAAATCACC) (Figure 2A) is completely homologous with the murine and human aldose reductase osmoregulatory elements $(13,45)$. We introduced a series of point mutations into the putative TonE in the Sgk1 promoter-driven luciferase reporter and transfected these into IMCD cells. As shown in Figure 2B, one of the mutations (M3) led to complete reversal of the osmotic induction, while 2 of the others, M1 and M2, led to intermediate levels of inhibition; a fourth, M4, with base modifications outside the core TonE, was without effect.

Given the previous association of the putative Sp1-binding element (34) with the osmotic induction of this promoter's activity, we created a mutation in this site, alone and in combination with the TonE mutation (Figure $3 \mathrm{~A}$ ), and introduced the reporters into IMCD cells. As shown in Figure 3B, virtually the entire osmotic induction appears to flow through TonE in these cells. Mutation of the Sp1-binding element in the GC-rich region did not affect the osmotic induction when tested alone or in the presence of the TonE mutation. Thus, while this Sp1-binding element appears to 


\section{A}

-335 GgGagaggaAatgGaAATCACCGAggCtCTCC -335 GGGAGAGGAAATaGAAATCACCGAGGCTCTCC WT -335 GGGAGAGGAAATGGgAATCACCGAGGCTCTCC M1 -335 GGGAGAGGAAATaAAAATCAtCGAGGCTCTCC $\mathrm{M} 2$ -335 GGGAGAGGAAATGGAAATCACtGAGGCTCTCC M3 M4

B

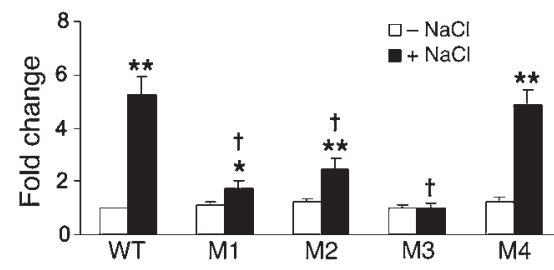

play a role in controlling the $S g k 1$ promoter response to tonicity in NMuMg cells (34), in IMCD cells the TonE site dominates in orchestrating this response.

In the case of the aldose reductase (13) and betaine transporter (20) genes, a specific nuclear transcription factor termed NFAT5 has been shown to associate with TonE and stimulate transcriptional activity of the contiguous promoter. To explore the involvement of NFAT5 as a mediator of the osmotic induction of the Sgk1 promoter, we carried out EMSA of nuclear extracts from IMCD cells cultured under isotonic versus hypertonic $(\mathrm{NaCl})$ conditions using radiolabeled $S g k 1$ TonE sequence as a probe. As shown in Figure 4A, exposure to the hypertonic environment resulted in an increase in protein association with the oligonucleotide harboring the TonE, here designated as the NFAT5 complex. Incubation with anti-NFAT5 antibody, but not with antibody directed against the p50 subunit of NF- $\kappa B$, resulted in a supershift of the associated protein. The NFAT5 complex was competed by unlabeled oligonucleotide harboring the wild-type sequence and by the sequence harboring the M4 mutation, but not by oligonucleotides harboring mutations M1, M2, or M3 (Figure 4B). Thus, the relative affinity of NFAT5 for these mutated osmotic response element (ORE) sequences mirrors the ability of these sequences to signal the osmotic induction of the Sgk1 promoter (see Figure 2).

Western blot analysis for NFAT5 protein showed that there was a shift of protein from the cytoplasm into the nuclear compartment after 4 hours of exposure to the hypertonic environment (75 $\mathrm{mM} \mathrm{NaCl}$ ), and this nuclear sequestration persisted for 24 hours (Figure 4, C and D). In addition, there was a net increase in levels of total NFAT5 protein at 24 hours that was not present at the 4-hour time point (Figure 4E).

\section{Figure 3}

Proximal Sp1-binding elements do not participate in the osmotic induction of Sgk1 promoter activity in rat IMCD cells. (A) Locations and targeted mutagenesis of the TonE- and Sp1-binding sites in the rat Sgk1 promoter. TonE- and Sp1-binding sequences are identified in bold, and mutated bases are indicated by lower-case letters. (B) Actin$\beta$-galactosidase $(0.2 \mu \mathrm{g})$ was cotransfected into IMCD cells with $1 \mu \mathrm{g}$ wild-type -1430 Sgk1-Luc or the M3 TonE mutant (TonE MUT), Sp1 mutant (Sp1 MUT), or a double mutant (TonE MUT/Sp1 MUT) and cultured for 24 hours. At that point, cells were treated with $75 \mathrm{mM} \mathrm{NaCl}$ or $150 \mathrm{mM}$ sucrose for 24 hours. ${ }^{* \star} P<0.01$ versus control $(n=3)$.

\section{Figure 2}

Mutation of TonE blocks osmotic induction of the $S g k 1$ gene promoter in IMCD cells. (A) Location and site-directed mutagenesis of the TonE site in the rat $S g k 1$ promoter. Mutagenized bases are indicated by lower-case letters. (B) Wild-type -1,430 Sgk1-Luc (1 $\mu \mathrm{g})$ or a series of TonE mutants (M1-M4) were cotransfected with $0.2 \mu \mathrm{g}$ actin- $\beta$-galactosidase into IMCD cells. The cells were cultured with or without 75 $\mathrm{mM} \mathrm{NaCl}$ for 24 hours prior to collection for luciferase and $\beta$-galactosidase measurement. ${ }^{* \star} P<0.01,{ }^{\star} P<0.05$ versus respective controls; † $P<0.01$ versus $\mathrm{NaCl}$ alone $(n=3)$.
To confirm that the osmotically dependent NFAT5 association with the $S g k 1$ promoter takes place within the context of the intact cell, we carried out ChIP analysis of the endogenous rat $S g k 1$ promoter using an antibody directed against NFAT5. As shown in Figure 5A, exposure of IMCD cells to hypertonic medium (addition of $75 \mathrm{mM} \mathrm{NaCl}$ or $150 \mathrm{mM}$ sucrose to culture medium) led to increased association of both NFAT5 and RNA polymerase II with the native $S g k 1$ gene relative to the isotonic control. Neither NFAT5 nor RNA polymerase II interacted to any significant degree with sequence lacking the TonE positioned $3.2 \mathrm{~kb}$ upstream from the Sgk1 gene. To prove that this interaction between NFAT5 and the $S g k 1$ gene promoter requires the TonE-binding sequence described above, we introduced reporter plasmids harboring 1,474 bp of rat $S g k 15^{\prime}$ flanking sequence $(-1,430$ to +44$)$ into IMCD cells by transient transfection. One of these reporters contained entirely wild-type sequence, while the other harbored a selective mutation (M3) in the TonE. As shown in Figure 5B, the wild-type sequence showed evidence of substantial osmosensitive association with NFAT5 in the ChIP assay; mutation of the TonE-binding site resulted in near complete loss of this association.

\section{A}

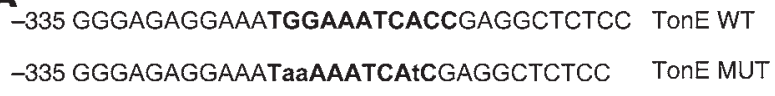

-67 CCTGGTCCCGCCTGCCCCGCCCCCTGGAGGCTC Sp1 WT -67 CCTGGTCCCGCCTGCCHGCaaCCTGGAGGCTC Sp1 MUT

-335 GGGAGAGGAAATaaAAATCAtCGAGGCTCTCC/ -67 CCTGGTCCCGCCTGCCttGCaaCCTGGAGGCTC TonE/Sp1 MUT

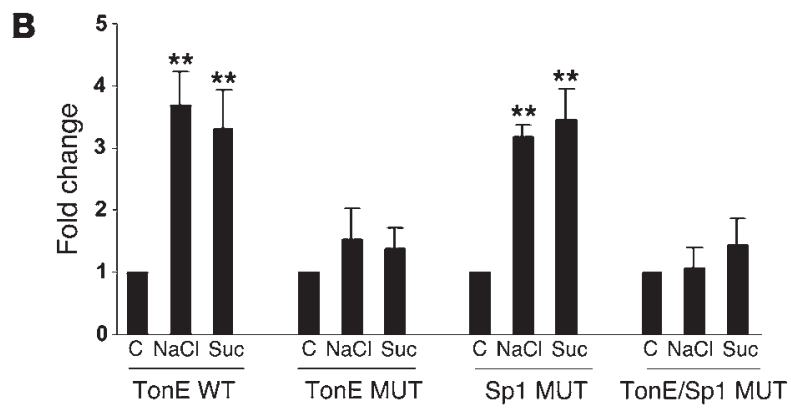



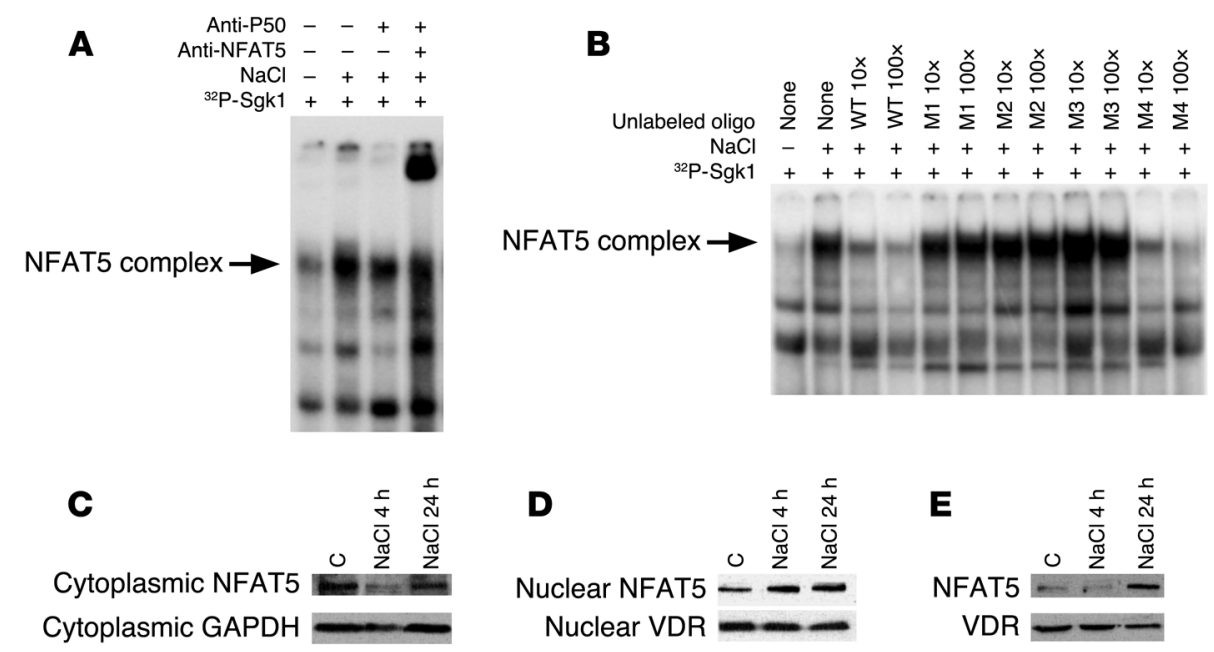

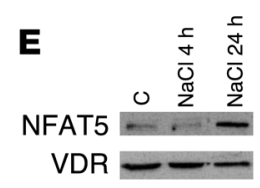

\section{Figure 4}

NFAT5 binding to TonE in the Sgk1 promoter in vitro. (A) Nuclear extracts were preincubated on ice for 2 hours with $1 \mu \mathrm{g}$ of polyclonal antibody directed against NFAT5 or the p50 subunit of NF-кB. ${ }^{32} \mathrm{P}$-end-labeled, double-stranded wild-type oligonucleotide containing the TonE sequence from the Sgk1 promoter ( ${ }^{32} \mathrm{P}-\mathrm{Sgk} 1$ ) was added to the reaction and incubated at room temperature for 30 minutes. (B) Nuclear extracts were incubated with ${ }^{32}$ P-labeled TonE-containing Sgk1 oligonucleotide in the absence or presence of increasing concentrations of unlabeled wild-type or mutant TonE-containing oligonucleotides (10- or 100-fold molar excess). The reaction complexes were resolved on $5 \%$ nondenaturing polyacrylamide gels. (C and D) Cytoplasmic extract was collected simultaneously with the nuclear extract, and $150 \mathrm{mM} \mathrm{NaCl}$ and $10 \%$ glycerol were added. Cytoplasmic and nuclear extracts were subjected to Western blot analysis with anti-NFAT5 antibody. NFAT5 signals were normalized to GAPDH and vitamin D receptor (VDR), respectively. (E) IMCD cells were lysed with regular lysis buffer, and total protein was used for immunoblotting. The NFAT5 signal was normalized to VDR. The experiments were repeated 2-4 times. Representative autoradiographs are shown.

To link the NFAT5 protein functionally to the osmotic induction of Sgk1 promoter activity, we used 2 different approaches to inhibit NFAT5 activity. Introduction of U6-N5 ex8, a small inhibitory RNA vector that specifically targets the NFAT5 endogenous transcript (46), completely reversed the osmotic induction of the Sgk1 promoter, while the empty U6 vector was devoid of activity (Figure 6). Similarly, introduction of a dominant negative NFAT5 expression vector (NFAT5-DN) along with the Sgk1-Luc reporter led to significant inhibition of the osmotic response. Collectively, these findings, along with the results presented above, support the hypothesis that NFAT5 is the relevant transcription factor that binds to the Sgk1 TonE and mediates the osmotic induction of that gene's promoter in IMCD cells.

A previous study by Rozansky et al. (47) demonstrated that sgk1 gene expression can also be activated by reductions in extracellular tonicity (i.e. hypoosmolality) in A6 cells. To evaluate this phenomenon in cultured IMCD cells and its dependence on the TonE site described above, we introduced the wild-type Sgk1-Luc or the TonE-mutated Sgk1-Luc into primary cultures of rat IMCD cells and exposed them to either a hyper- or a hypotonic environment. As shown in Figure 7, relative to the cells cultured in isotonic medium, cells exposed to either the hypo- or hypertonic medium showed a significant increase in expression of the wild-type Sgk1 promoter. However, while mutation of the TonE, as expected, led to a near complete inhibition of the hypertonic stimulation of promoter activity, it had virtually no effect on the hypotonic stimulation. This implies that the hypotonic stimulation of Sgk1 gene transcription operates over signaling pathways that are largely independent of those used for the hypertonic induction, including NFAT5 and the TonE.

As mentioned above, expression of both Sgk1 and NPR-A has been shown to increase in IMCD cells exposed to increased extracellular tonicity. To establish the link between Sgk1 and the induction of NPR-A gene expression, we employed an siRNA approach. Cultured rat IMCD cells were transfected with one of 3 siRNA sequences, each of which was designed to target the rat $S g k 1$ gene coding sequence, prior to exposure of the cells to increased extracellular tonicity $(75 \mathrm{mM} \mathrm{NaCl})$. As shown in Figure 8A, exposure to hypertonic culture media resulted in a 4- to 5 -fold increase in Sgk1 mRNA expression in these cells. This increment was partially reduced by siSgk $1 \mathrm{~A}$ and siSgk1B and nearly completely eliminated by cotransfection with siSgk1C. Similarly, as shown in the Western blot in Figure 8B, siSgk1C had little effect on basal levels of Sgk1 protein, but it nearly completely reversed the $\mathrm{NaCl}$ dependent increment in Sgk1. The same level of extracellular tonicity (75 $\mathrm{mM} \mathrm{NaCl}$ ) led to a 3-fold increase in NPR-A mRNA levels (Figure 8C) and a 4 -fold increment in NPR-A protein levels (Figure 8D) in IMCD cells. Transfection of these cells with siSGK1C inhibited the increase in NPR-A protein and mRNA by approximately $60 \%$. Collectively, these data indicate that the osmotic induction of Sgk1 is a major contributor to the osmotic stimulation of NPR-A gene expression in IMCD cells.

To extend this observation to an in vivo model, we subjected male Sprague-Dawley rats to 24 hours of water deprivation, a procedure that is known to increase urine osmolality $(4,8,10,26,43)$ and renal medullary sodium concentration $(4,42,43)$. As shown in Table 1, water deprivation resulted in a significant increase in urine osmolality ( $40 \%$ increase over the baseline urine osmolality). There was a modest, but not statistically significant, increase in plasma osmolality, and no significant change in systolic or diastolic blood pressure in these 2 groups. The water-restricted animals lost approximately $10 \%$ of their body weight over the 24 -hour period, while weights in the control animals were stable.

Water restriction was associated with a statistically significant increase in urinary sodium excretion (Figure 9A), confirming the presence of the dehydration natriuresis observed by others in rats, rabbits, sheep, mice, dogs, and humans (1-11) following shortterm water restriction. This was accompanied by a significant increase in Sgk1 mRNA (Figure 9B) and Sgk1 protein (Figure 9C) in the renal IMCD. Because Sgk1 gene expression is known to be regulated by aldosterone, we measured plasma aldosterone levels at the end of the water deprivation period. As reported in Table 1, there was no change in plasma aldosterone levels after 24-hour water deprivation, a finding that is consistent with previous dehy- 
A
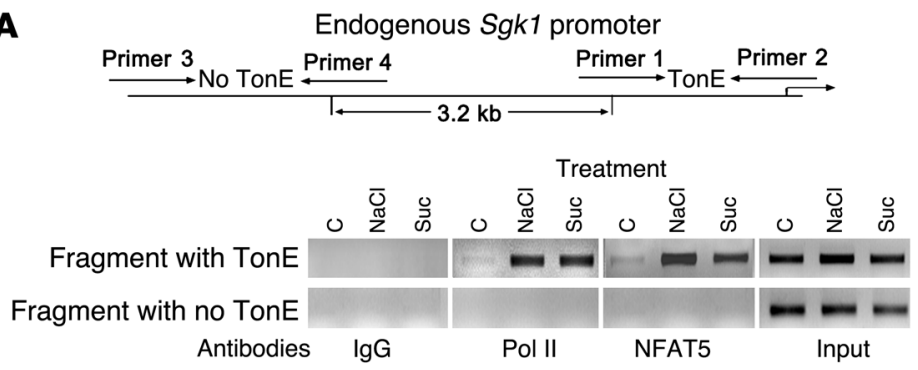

B

$\stackrel{\text { Primer } 1}{\longrightarrow}$ TonE $\stackrel{\text { Sgk1 promoter-Luc }}{\longrightarrow} \stackrel{\text { Primer } 5}{\longrightarrow}$ Luciferase

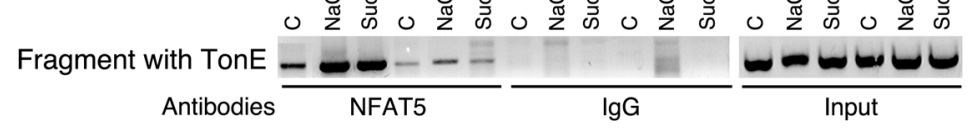

\section{Figure 5}

ChIP analysis of the Sgk1 promoter. (A) $\mathrm{NaCl}$ and/or sucrose treatment increases Sgk1 promoter activity. IMCD cells were exposed to $75 \mathrm{mM} \mathrm{NaCl}$ or $150 \mathrm{mM}$ sucrose for 24 hours. Extracts were generated, cross-linked with formaldehyde, fragmented by sonication, and immunoprecipitated with antibody directed against NFAT5 or RNA polymerase II (Pol II) or with nonimmune IgG. Associated DNA fragments were amplified for Sgk1 promoter sequence or unrelated promoter sequence positioned $3.2 \mathrm{~kb}$ upstream from the $S g k 1$ gene (top panel). Products were then size-fractionated on a $1 \%$ agarose gel. Signal generated from input chromatin (i.e., without immunoprecipitation) is shown in the bottom panel. The lanes were run on the same gel but were noncontiguous. (B) TonE mutation dramatically reduces osmotically induced NFAT5 binding to the Sgk1 promoter in IMCD cells. The experiment was carried out using transfected wild-type Sgk1 promoter or the M3 promoter mutant as described in Methods. Twentyfour hours after transfection, cells were challenged with $\mathrm{NaCl}$ or sucrose for 24 hours and then processed as described above. Representative results are shown $(n=3)$. dration studies $(3,9,11)$. Since some studies $(48,49)$ have shown that increased Sgk1 expression is linked to increased epithelial sodium channel $(\mathrm{ENaC})$ expression, we asked whether dehydration-induced Sgk1 expression was associated with increased $\mathrm{ENaC}$ expression. As shown in Figure 9D, water restriction modestly increased expression of the $\alpha$ subunit of $\mathrm{ENaC}(\alpha \mathrm{ENaC})$. However, this modest elevation in $\alpha E N a C$ expression was accompanied by increased sodium excretion rather than sodium absorption (see Figure 9A), implying that Sgk1-mediated activation of natriuresis plays a dominant physiological role in this special circumstance.

The increase in Sgk1 expression was accompanied by an increase in NPR-A mRNA (Figure 10A) and protein (Figure 10B), which, in turn, were linked to a 3-fold increase in urinary cyclic GMP excretion (Figure 10C). Cyclic GMP is the biological end product of NPR-A activation (i.e., ligand-dependent guanylyl cyclase activation).

To investigate a possible role for the ligand itself (i.e., ANP) in contributing to this increase in urinary cyclic GMP, we measured ANP mRNA transcript levels in the atria of the control versus water-restricted rats, as well as plasma ANP levels in the 2 groups. As shown in Figure 10, D and E, water restriction reduced, rather than increased, expression of the atrial ANP gene and circulating levels of ANP.

The kidney itself is also thought to be a source of ANP gene expression. Cells of the distal nephron have been shown to harbor proANP gene transcripts and ANP immunoreactivity (50), and ANP immunoreactivity has been identified in the urine (51). Urinary ANP, termed urodilatin, is a product of the renal ANP gene with a 4-amino-acid $\mathrm{N}$-terminal extension (supplied from the proANP precursor) linked to the core ANP peptide (52). As shown in Figure $10 \mathrm{~F}$, expression of proANP mRNA in the inner medulla is increased following 24 hours of water restriction, as is the excretion of urodilatin in urine (Figure 10G) (urodilatin concentration in urine: control, $4.37 \pm 0.64 \mathrm{pg} / \mu \mathrm{l}$ vs. dehydrated, $9.33 \pm 1.01 \mathrm{pg} / \mu \mathrm{l} ; P<0.01$ ), suggesting that locally generated ligand as well as increased expression of the NPR-A receptor (see above) contribute to the increased urinary excretion of sodium in the acutely dehydrated state.

To confirm the mechanistic link between dehydration natriuresis and increased NPR-A expression, we examined the effect of 24-hour water restriction in wild-type and $\mathrm{Npr}^{-/-}$(i.e., NPR-A gene-deleted) mice. As noted previously (53), $N p r 1^{-/-}$mice display significant hypertension compared with control littermates (systolic BP, $112.8 \pm 10.6$ vs. $103.8 \pm 6.9 \mathrm{mmHg}, P<0.01$; diastolic BP, $96.8 \pm 12.5$ vs. $83.3 \pm 8.1 \mathrm{mmHg}, P<0.05)$. Twenty-four hours of water deprivation resulted in weight loss (12\% in wild-type and $13 \%$ in $\mathrm{Npr1}^{-/-}$ mice) and increased urine osmolality in wild-type and $\mathrm{Npr}^{-1-}$ mice compared with their respective control littermates with free access to water (wild-type, $3,123.4 \pm 606.4$ vs. $1,817.9 \pm 401.5 \mathrm{mOsm} / \mathrm{kg}$ $\mathrm{H}_{2} \mathrm{O}, \mathrm{P}<0.01 ; \mathrm{Npr1}^{-/-}, 2,415.6 \pm 549.1$ vs. $1,568.8 \pm 578.5 \mathrm{mOsm} /$ $\mathrm{kg} \mathrm{H}_{2} \mathrm{O}, P<0.01$ ). This was accompanied by a significant increase in Sgk1 protein expression in IMCD (Figure 11A), suggesting that hyperosmolality activates Sgk1 expression in this nephron segment in both wild-type and $\mathrm{Npr}^{-1-}$ mice. Urinary sodium excretion was markedly increased during 24 hours of water restriction in wildtype mice (Figure 11B); however, this natriuresis did not occur in Npr1 $1^{-1-}$ mice (Figure 11B). As expected, dehydration dramatically increased NPR-A expression in wild-type mice; there was no NPR-A protein expression in $\mathrm{Npr}^{-/-}$mice (Figure 11C). NPR-A activity,

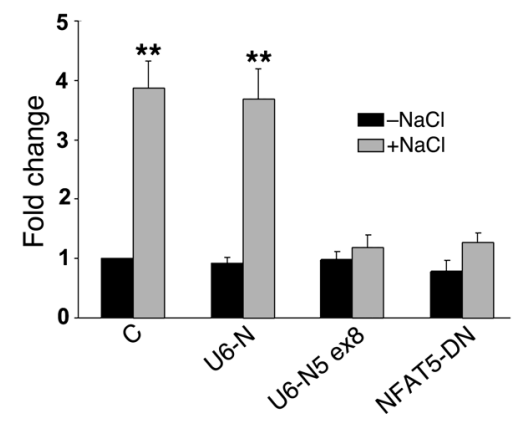

\section{Figure 6}

Selective inhibition of NFAT5 leads to blockade of the hypertonic induction of the Sgk1 gene promoter. A scrambled shRNA as a negative control (U6-N), an shRNA construct that targets NFAT5 (U6-N5 ex8), and a dominant negative mutant (NFAT5-DN) directed against NFAT5 inhibit the osmotic induction of the cotransfected Sgk1 promoter. The experiment is described in Methods. ${ }^{\star \star} P<0.01$ versus without $\mathrm{NaCl}(n=3)$. 


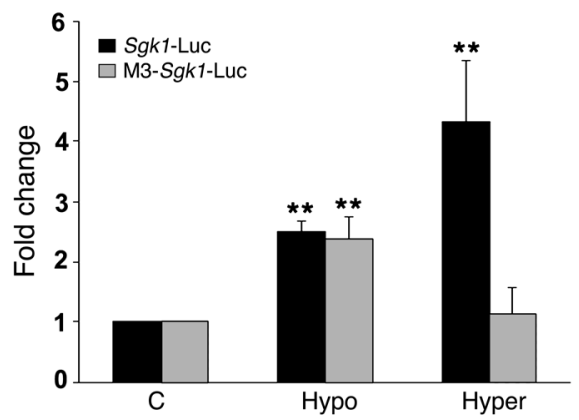

assessed as urinary cyclic GMP excretion, was significantly increased in dehydrated wild-type but not in dehydrated $\mathrm{Npr}^{-/-}$mice (Figure 11D). These findings support a mechanistic link between dehydration-induced natriuresis and NPR-A signaling activity.

\section{Discussion}

The signaling kinase Sgk1 is known to be regulated by extracellular tonicity (34-38). However, the mechanism underlying this regulation remains only partially understood. Previous studies by Bell et al. (34) using HMuMg mammary epithelial cells showed that Sgk1 gene promoter activity increased in response to extracellular hypertonicity; however, their results suggested that this increase was heavily dependent on a GC-rich segment of the proximal promoter that appeared to bind to the transcription factor Sp1. In our study, this particular Sp1 site or sites did not contribute

\section{Figure 7}

Hypotonic induction of the Sgk1 promoter does not require TonE. Wild-type -1,430 Sgk1-Luc (1 $\mu \mathrm{g})$ or M3-Sgk1-Luc (1 $\mu \mathrm{g})$ together with actin- $\beta$-galactosidase $(0.2 \mu \mathrm{g})$ were transfected into IMCD cells. After 24 hours, cells were exposed to hypotonic medium (Hypo; $220 \mathrm{mOsm} /$ $\mathrm{kg}$ water) or hypertonic medium (Hyper; $75 \mathrm{mM} \mathrm{NaCl}$; final osmolality, $446 \mathrm{mOsm} / \mathrm{kg}$ water) for 24 hours. Pooled data $(n=3)$ representing normalized $S g k 1$-Luc activity are shown. ${ }^{* \star} P<0.01$ versus control. greatly to the osmotic induction of Sgk1 in primary cultures of rat IMCD cells. Instead, virtually all of the osmoregulatory activity required the presence of an intact TonE element much further upstream in the promoter. The reason(s) behind this differential response remain undefined, but the data suggest that different cell types may use different mechanisms to forge the signal linking extracellular tonicity to the transcriptional machinery. $\mathrm{HMuMg}$ cells, as mammary epithelial cells, exist largely in an isotonic environment in their natural location in vivo, while IMCD cells are positioned in the medulla of the kidney. This region is subject to wide swings in extracellular tonicity, and it plays a key role in linking tonicity to physiological responses. It is possible, therefore, that IMCD cells have refined the osmoregulatory signals responsible for controlling Sgk1 gene expression beyond those available to mammary epithelial cells.
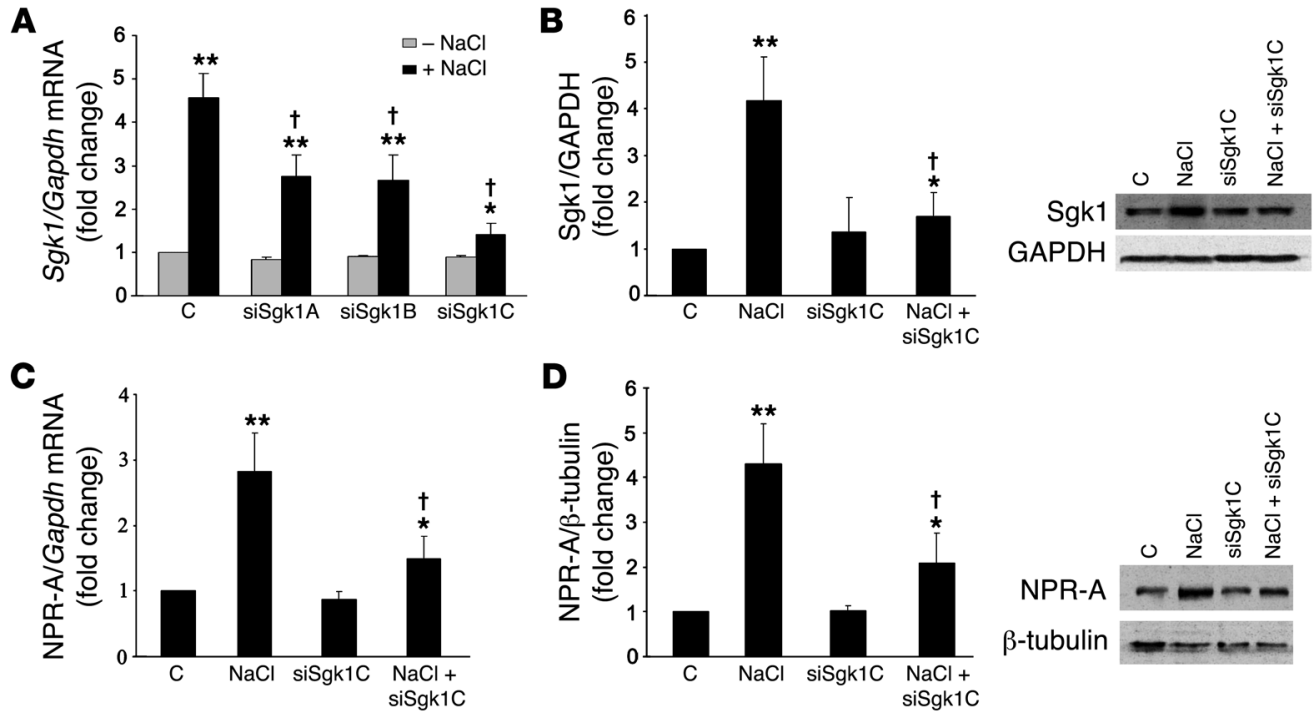

Figure 8

Sgk1 siRNA blocks NaCl-induced Sgk1 and NPR-A gene transcription and translation. Three different Sgk1 siRNAs (siSgk1A, siSgk1B, siSgk1C) (A) and a negative control siRNA (C) were individually transfected into IMCD cells for 48 hours. Three hours prior to isolation of RNA, cells were treated with or without $75 \mathrm{mM} \mathrm{NaCl}$. Total RNA was obtained for measurement of Sgk1/Gapdh mRNA by real-time PCR. (B) IMCD cells were transfected with control siRNA and siSgk1C for 41 hours and then exposed to control medium and $75 \mathrm{mM} \mathrm{NaCl}$ for $7 \mathrm{hours}$. Afterward, cells were harvested, and total protein was assayed for Sgk1 and GAPDH expression by Western blot analysis. Sgk1 expression was normalized to GAPDH protein levels. (C) siSgk1C or control siRNA was individually transfected into IMCD cells for 28 hours. Subsequently, cells were incubated with or without $75 \mathrm{mM} \mathrm{NaCl}$ for 20 hours. Total RNA was collected, and NPR-A/Gapdh mRNA levels were measured by real-time PCR. (D) In a separate experiment, after 24 hours of transfection with siSgk1C or control siRNA, cells were treated with or without 75 $\mathrm{mM} \mathrm{NaCl}$ for 24 hours. Membrane proteins were prepared as described in Methods and used to assay NPR-A/ $\beta$-tubulin expression by Western blot analysis. All experiments were repeated $3-4$ times. Representative immunoblotting results are shown. ${ }^{* *} P<0.01,{ }^{*} P<0.05$ versus control; ${ }^{\dagger} P<0.01$ versus $\mathrm{NaCl}$ alone. 
Table 1

Effect of 24-hour water restriction on plasma aldosterone levels, plasma and urine osmolality, blood pressure, and body weight (before and after dehydration)

\begin{tabular}{lcccccc} 
& $\begin{array}{c}\text { Aldosterone } \\
\mathbf{( p g} / \mathbf{m l})\end{array}$ & $\begin{array}{c}\text { Urine 0SM } \\
(\mathbf{m 0 s m} / \mathbf{k g ~ H} \mathbf{0})\end{array}$ & $\begin{array}{c}\text { Plasma 0SM } \\
(\mathbf{m 0 s m ~ H} \mathbf{0})\end{array}$ & $\begin{array}{c}\text { BP } \\
(\mathbf{m m H g})\end{array}$ & \multicolumn{2}{c}{ BW $(\mathbf{g})$} \\
Control & $1,486 \pm 148$ & $1,820 \pm 204$ & $305 \pm 10$ & $115 \pm 10 / 91 \pm 6$ & $283 \pm 9$ & $287 \pm 10$ \\
Dehydration & $1,472 \pm 88$ & $2,546 \pm 218^{A}$ & $310 \pm 9$ & $111 \pm 13 / 88 \pm 8$ & $278 \pm 8$ & $251 \pm 9^{B}$ \\
\hline
\end{tabular}

OSM, osmolality. ${ }^{A} P<0.01$ versus control. ${ }^{B} P<0.01$ versus prior to water restriction. $n=8$.

Sgk1 could, by analogy to the gene products listed above, function to dampen or inhibit the sequelae attendant to increased extracellular tonicity, as occurs with dehydration following water restriction. At the organismal level, this appears to involve increased activity of the natriuretic peptide system and enhanced urinary sodium excretion, an effect that would counter increased extracellular tonicity

NFAT5 levels have been shown to increase in a linear fashion with increases in extracellular tonicity (54). Nuclear TonEBP is increased throughout the medulla in dehydrated versus water-loaded animals (26). It is noteworthy that Rozansky et al. showed that sgk1, in addition to being stimulated by increases in extracellular tonicity, is also stimulated by decreases in extracellular tonicity (47). The latter has been demonstrated using hypo-osmotic induction of A6 cells and confirmed here using rat IMCD cells. The biphasic response of the Sgk1 promoter would be difficult to explain using a single NFAT5dependent regulatory mechanism, and in fact, our results suggest that only the response to hypertonicity is NFAT5/TonE dependent. This implies that the hypotonic induction of Sgk1 gene transcription operates independently of NFAT5 and the TonE.

Several genes have been shown to respond to extracellular tonicity with altered expression $(55,56)$. A significant number of these, including the betaine/GABA transporter gene (14), the sodiummyoinositol cotransporter gene (17), the heat shock protein HSP70 gene (16), the urea transporters encoded by the UT-A gene (18), the TNF gene (46), the aquaporin 2 gene (19), and aldose reductase genes (13) respond through an NFAT5/TonEBP-binding element (TonE) in their respective promoters. Several of these exert counterregulatory activity that, at least in part, serves to dampen the effects of increased extracellular tonicity. The inositol and betaine transporters, for example, raise intracellular osmolality without increasing ionic strength, thereby protecting the cell from the damaging effects of the latter $(14,17)$. However, most of these gene products act passively to protect cells from hypertonicity. To date, no tonicity-induced genes have been identified that functionally feed back to increase the excretion of sodium, the dominant contributor to plasma tonicity. The demonstrated osmosensitivity of the Sgk1 gene promoter and the demonstration that this sensitivity is dependent upon an NFAT5-binding TonE element between -324 and -312 bp in the promoter supports the hypothesis that Sgk1 is a physiological target of extracellular tonicity in the IMCD.

\section{Figure 9}

Water restriction increases urine sodium excretion, Sgk1 mRNA, and protein levels in rat IMCD. (A) Urine from control rats or rats dehydrated (Dehy) for 24 hours was collected twice ( 9 and 24 hours into dehydration), and urine from the final 15 hours was used to measure volume, sodium concentration, and urine $\mathrm{Na}$ excretion rate (UNa V). Pooled data $(n=10)$ are shown. (B) Rats were euthanized, and renal medullas were isolated for RNA and protein preparation. Real-time PCR was performed for analysis of $\operatorname{Sgk} 1$ and Gapdh mRNA levels. Western blot analysis was used to measure Sgk1 and GAPDH protein levels $(\mathbf{C})$ and $\alpha \mathrm{ENaC}$ and GAPDH protein levels (D). Representative results and pooled data $(n=6)$ are presented. ${ }^{\star *} P<0.01,{ }^{\star} P<0.05$ versus control. through reduction of extracellular solute levels.

Dehydration-induced natriuresis has been described in a variety of mammalian species including rats, rabbits, sheep, mice, dogs, and humans (1-11). It typically occurs within the first 24-48 hours following the onset of water restriction, presumably before significant contraction of intravascular volume has occurred. It is characterized by a moderate increase in urinary sodium excretion that gradually wanes as volume contraction and mechanisms associated with increased renal sodium retention come to dominate the physiology. The mechanism underling this natriuresis remains unclear. Data have been presented suggesting that the neurohypophyseal hormone oxytocin may participate in this natriuresis. Levels of plasma oxytocin increase slightly in water-restricted states, concomitant with the natriuresis (2). However, oxytocin infusion in humans placed on either a high- or low-salt diet proved incapable of producing natriuresis (57).

We have shown previously that increased extracellular tonicity leads to an increase in NPR-A gene expression and NPR-A activity (41), with concomitant increased expression of Sgk1 (40). We have hypothesized that it is Sgk1 that mediates the increase in NPR-A expression, a hypothesis that draws strength from the siRNA stud-
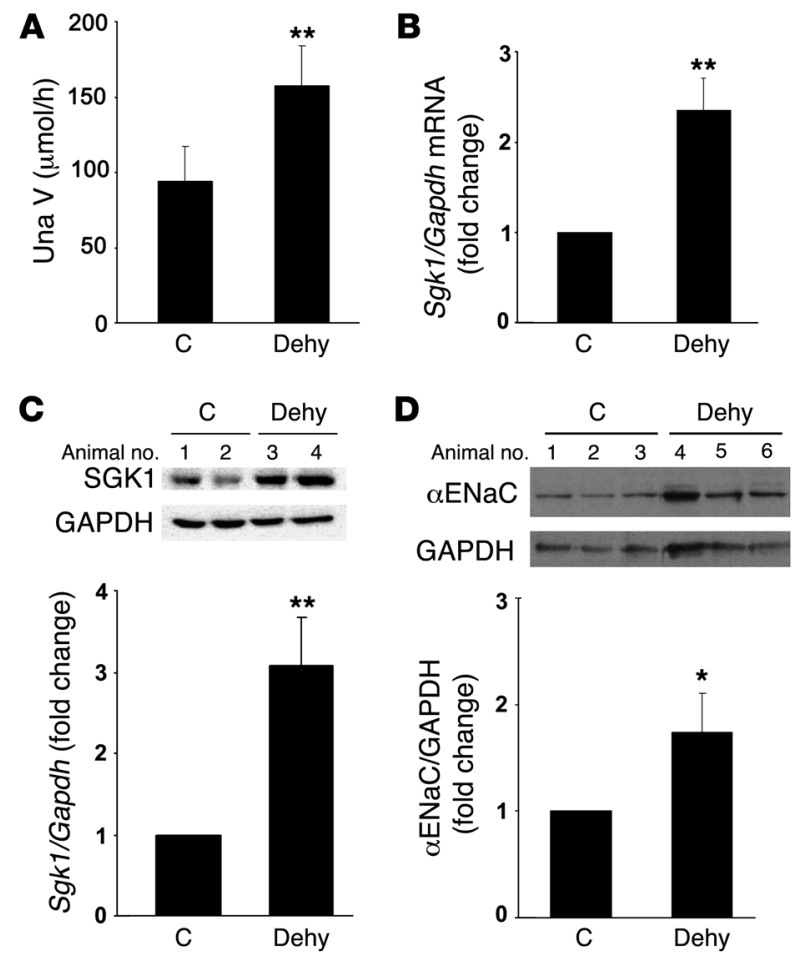


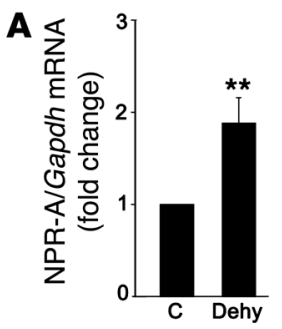

$\mathbf{B}$

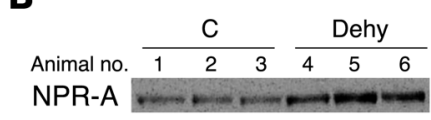

$\beta$-tubulin $-\infty-$
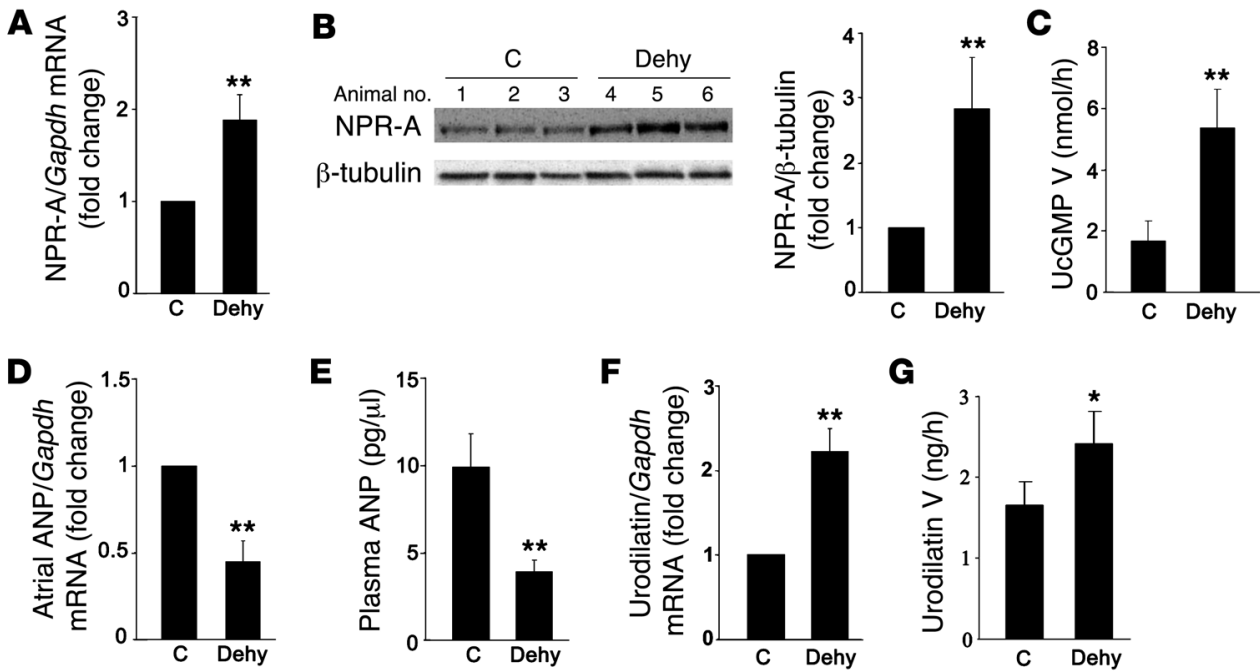

E

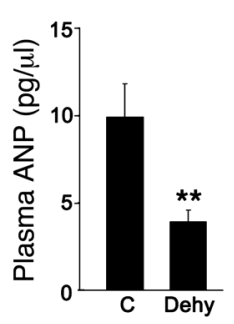

$\mathbf{F}$

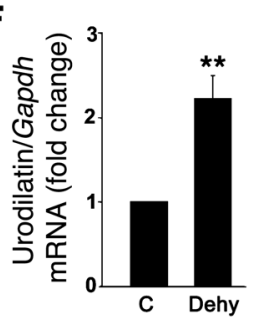

G

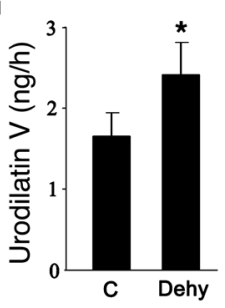

Figure 10

Dehydration activates the natriuretic peptide system in rat IMCD. (A) Renal medullas from control rats or rats subjected to 24 hours of dehydration were used to prepare total RNA and membrane protein. NPR-A and Gapdh mRNAs were measured by real-time PCR. Pooled data $(n=8)$ are shown. (B) NPR-A and $\beta$-tubulin in membrane protein fractions were determined by immunoblot. NPR-A levels are normalized for $\beta$-tubulin expression. Representative results and pooled data $(n=10)$ are shown. (C) Urine of control rats or water-restricted rats from the final 15 hours of dehydration was used to measure urinary cGMP excretion rates (UcGMP V). Pooled data $(n=10)$ are shown. (D) After 24 hours of dehydration, the left atria were isolated for preparation of total RNA. ANP and Gapdh mRNA levels were measured by realtime PCR. Pooled data $(n=8)$ are presented. (E) Plasma was used to determine ANP levels. The data are derived from 8 animals in each group. (F) Renal medullas were used to measure urodilatin and Gapdh mRNA by real-time PCR. Pooled data $(n=8)$ are shown. $(\mathbf{G})$ Urine was used to measure urodilatin excretion rates (Urodilatin $\mathrm{V}$ ) in 8 animals in each group. ${ }^{\star *} P<0.01,{ }^{*} P<0.05$ versus control.

ies presented here. Under conditions where the osmotic induction of Sgk1 gene expression in IMCD cells is almost completely suppressed by an appropriately targeted siRNA, there is a parallel reduction in NPR-A gene expression. This implies a mechanistic link between these 2 signaling pathways.

Extrapolating this to the in vivo paradigm, there was a concomitant increase in Sgk1 and NPR-A gene expression in the renal medulla of the intact rat and mouse that was accompanied by increased urinary cGMP and sodium excretion following only 24 hours of water restriction. Dehydration of $\mathrm{Npr}^{-/-}$mice elevated urinary osmolality and Sgk 1 expression in the renal medulla but failed to elicit changes in urinary cGMP or sodium excretion. We believe that this supports our hypothesis that the liganded NPR-A in the distal nephron is a critical contributor to dehydration-induced natriuresis.

While we have carried out the majority of our studies using IMCD, it is conceivable, if not probable, that other distal nephron segments (e.g., outer medullary or cortical collecting duct) participate in generating the natriuresis. In fact, we have examined the osmotic response to water restriction in rat renal outer medullary tissue and found a similar increase in Sgk1 and NPR-A expression, though the increases were smaller than those seen for IMCD (S. Chen, unpublished observations).

Recent work by Rubera et al. (58) demonstrated that targeted deletion of the gene encoding the $\alpha \mathrm{ENaC}$ from the collecting duct of the mouse had no major effect on sodium homeostasis. We interpret this finding to mean that $\mathrm{ENaC}$ activity in the collecting duct is dispensable with regard to the maintenance of sodium balance at steady state. It could reflect the fact that the collectsignificantly increase urinary sodium excretion. This natriuresis occurs under conditions where renal ANP gene regulation is in direct opposition to that of its atrial counterpart, implying that a totally independent regulatory circuitry governs its expression. The details of this regulatory circuitry remain undefined. It does not appear to be osmoregulatory, since hypertonicity does not increase ANP gene expression in isolated cortical or medullary collecting duct cells (data not shown).

Collectively, these studies and those of others (1-11) indicate that physiological systems, independent of those that control water intake and retention, are in place to protect the upper border of serum sodium concentration. Under conditions where intravascular volume is largely preserved, these systems are capable of promoting an increase in urinary sodium excretion. We believe that this occurs, at least in part, through activation of the natriuretic peptide-dependent signaling system in the distal nephron, an effect that requires the osmotic stimulation of Sgk1 gene expression. This renal natriuretic peptide system would be predicted to play an important role in dampening swings in serum sodium concentration attendant to transient periods of water deprivation. One might also envision that aberrant activation of this system could contribute to the paradoxical increase in renal sodium wasting seen in the syndrome of inappropriate antidiuretic hormone secretion $(62,63)$ or cerebral salt wasting syndrome (62).

\section{Methods}

Plasmid construction and mutagenesis. A 1,430-bp segment of 5' flanking sequence from the rat Sgk1-CAT reporter provided by Gary Firestone (Uni- 

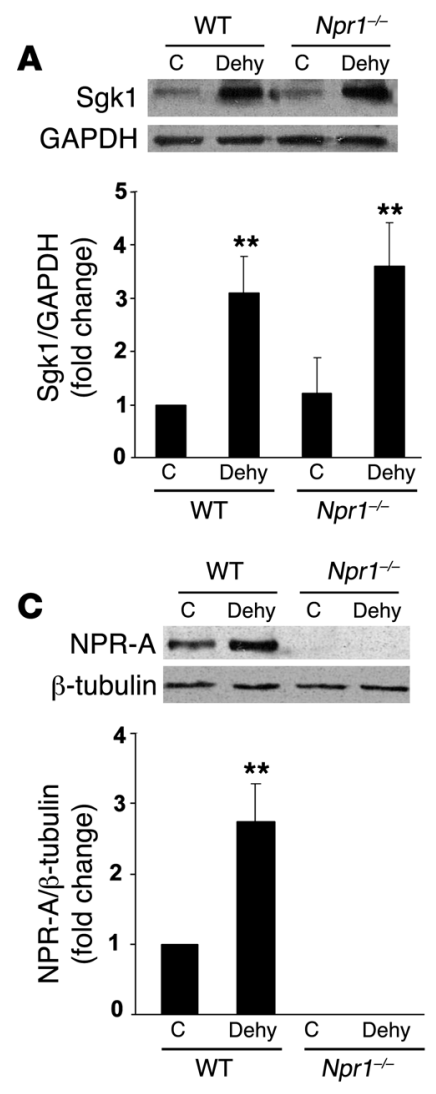

B

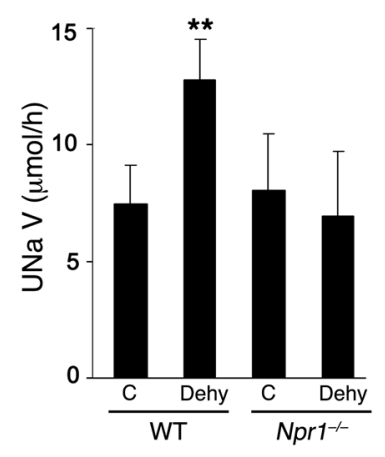

D

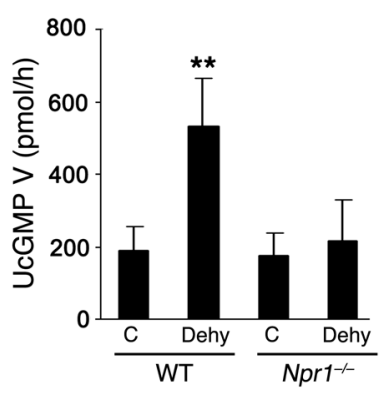

versity of California Berkeley, Berkeley, California, USA) was amplified and subcloned into pGL3 using newly generated $\mathrm{KpnI}$ and BglII restriction sites at opposing ends of the fragment. The structure was confirmed by DNA sequencing. Mutagenesis of the putative TonE (-335 GGGAGAGGAAATGGAAATCACCGAGGCTCTCC; TonE underlined) was carried out using the QuikChange Mutagenesis Kit (Stratagene) and the following series of oligonucleotides (sequence represents sense strand, with mutagenized bases represented in lower case): M1 (-335 GGGAGAGGAAATaGAAAATCACCGAGGCTCTCC), M2 (-335 GGGAGAGGAAATGGgAAATCACCGAGGCTCTCC), M3 (-335 GGGAGAGGAAATaaAAAATCAtCGAGGCTCTCC), and M4 (-335 GGGAGAGGAAATGGAAAATCACtGAGGCTCTCC). A GC-rich region spanning an Sp1-binding site was identified in the Sgk1 gene promoter previously (34) (-67 CCTGGTCCCGCCTGCCCCGCCCCCTGGAGGCTC; Sp1-binding site underlined). An Sp1 mutant (-67 CCTGGTCCCGCCTGCCttGCaaCCTGGAGGCTC) was created in this promoter using base modifications identical to those reported previously (34). The M3/Sp1 mutant (-335 GGGAGAGGAAATaaAAAATCAtCGAGGCTCTCC/-67 CCTGGTCCCGCCTGCCttGCaaCCTGGAGGCTC) was generated using combined mutagenesis of the promoter.

Primary cultures of rat IMCD cells. All experiments in animals were reviewed and approved by the IACUC of UCSF. Adult Sprague-Dawley rats were euthanized by $\mathrm{CO}_{2}$ narcosis, followed by bilateral thoracotomy. The inner medullary tissue of each kidney was dissected, minced, and digested with $1 \mathrm{mg} / \mathrm{ml}$ collagenase at $37^{\circ} \mathrm{C}$, with gentle agitation during each 30 -minute cycle. The preparation was enriched for IMCD cells using hypotonic lysis as described previously (64). Cells were resuspended in medium-1 (65) and seeded onto culture plates. After 18-24 hours, the medium was changed to K-1 medium (65) prior to initiation of the experiment.

Preparation of nuclear extracts. IMCD cells were cultured and treated with vehicle or $\mathrm{NaCl}$ for $4-5$ hours. Cells were harvested and lysed with buffer $\mathrm{A}$

\section{Figure 11}

Effect of water restriction on the Sgk1/NPR-A signaling pathway in wild-type and $\mathrm{Npr1}^{-/-}$mice. (A) Control and 24-hour water-restricted mice were euthanized, and IMCD was isolated for total protein preparation. Sgk1 and GAPDH protein levels were measured by Western blot analysis. Representative blot and pooled data $(n=5)$ are shown. (B) Urine from control mice and mice dehydrated for 24 hours was collected in the final 15 hours. Urine volume and sodium were measured $(n=9)$. (C) Isolated renal inner medulla was used to prepare membrane protein. NPR-A expression was determined by Western blot analysis and normalized to $\beta$-tubulin content. Representative results and pooled data $(n=4)$ are presented. (D) Urinary cGMP excretion was measured during the final 15 hours of water restriction $(n=9)$. ${ }^{\star \star} P<0.01$ versus the relevant control.

(10 mM HEPES, pH 7.9, $1.5 \mathrm{mM} \mathrm{MgCl}_{2}, 10 \mathrm{mM} \mathrm{KCl}, 0.5 \%$ Nonidet P-40, $1 \mathrm{mM}$ dithiothreitol, protease inhibitor cocktail [1 Complete tablet/50 $\mathrm{ml}$; Roche]) on ice for 10 minutes. Lysates were centrifuged for 5 minutes at $4{ }^{\circ} \mathrm{C}$. Supernatants were transferred to new tubes and adjusted to 150 $\mathrm{mM} \mathrm{NaCl}$ and $10 \%$ glycerol prior to Western blot analysis for cytoplasmic NFAT5. Particulates were resuspended in buffer C (20 mM HEPES, pH 7.9, $420 \mathrm{mM} \mathrm{NaCl}, 1.5 \mathrm{mM} \mathrm{MgCl}_{2}, 0.2 \mathrm{mM}$ EDTA, $25 \%$ glycerol, and the protease inhibitor cocktail) and kept on ice for 30 minutes. Nuclear suspensions were centrifuged at 12,800 $\mathrm{g}$ for 10 minutes, and the nuclear extracts were stored at $-80^{\circ} \mathrm{C}$ for later EMSA or immunoblotting.

EMSA. Oligonucleotides used for EMSAs were as follows: wildtype: (-335 GGGAGAGGAAATGGAAAATCACCGAGGCTCTCC); M1 (-335 GGGAGAGGAAATaGAAAATCACCGAGGCTCTCC); M2 (-335 GGGAGAGGAAATGGgAAATCACCGAGGCTCTCC); M3 (-335 GGGAGAGGAAATaaAAAATCAtCGAGGCTCTCC); M4 (-335 GGGAGAGGAAATGGAAAATCACtGAGGCTCTCC). The oligonucleotides containing the wild-type or mutant (lower-case lettering) OREs (underlined) were annealed with their complementary primer sequence and purified using a QIAquick Nucleotide Removal Kit (QIAGEN). Nuclear extracts (5 $\mu \mathrm{g})$ were incubated in binding reaction buffer [10 mM HEPES, pH 7.9, $50 \mathrm{mM} \mathrm{KCl}$, $0.2 \mathrm{mM}$ EDTA, $2.5 \mathrm{mM}$ dithiothreitol, $10 \%$ glycerol, and $0.05 \%$ Nonidet $\mathrm{P}-40$, containing $1 \mu \mathrm{g}$ of poly $(\mathrm{dI}-\mathrm{dC})]$ and ${ }^{32} \mathrm{P}$-end-labeled double-stranded wild-type oligonucleotide at room temperature for 30 minutes. For immunoperturbation experiments, nuclear extracts were preincubated on ice for 2 hours with $1 \mu \mathrm{g}$ of polyclonal antibody directed against NFAT5 (Affinity BioReagents) or the p50 subunit of NF- $\mathrm{\kappa B}$ (Santa Cruz Biotechnology Inc.). NFAT5 antibody used in pilot experiments was provided by $\mathrm{H}$. Moo Kwon (University of Maryland School of Medicine, Baltimore, Maryland, USA). All samples were resolved on $4 \%$ nondenaturing polyacrylamide gels. Gels were dried and exposed to X-ray film.

Transfection and luciferase assay. IMCD cells were cultured as described above and then transiently transfected with $1 \mu \mathrm{g}$ of $-1,430$ rat Sgk1-luciferase (wild-type or mutant) and $0.2 \mu \mathrm{g}$ of actin- $\beta$-galactosidase, in the presence or absence of U6 shRNA-NFAT5 (U6-N5 ex8) or a scrambled shRNA as a negative control (U6-N) (46) or NFAT5-DN (46), a dominant negative mutant of NFAT5, using Lipofectin Reagent (Invitrogen) under conditions recommended by the manufacturer. U6 shRNA-NFAT5 and NFAT5-DN were gifts from Anne Goldfeld (Harvard Medical School, Boston, Massachusetts, USA). Twenty four hours after transfection, cells were treated with $75 \mathrm{mM}$ $\mathrm{NaCl}$ or $150 \mathrm{mM}$ sucrose in DMEM $\left(296 \mathrm{mOsm} / \mathrm{kg} \mathrm{H}_{2} \mathrm{O}\right)$ for 24 hours, after which cells were washed twice with PBS and lysed with passive lysis buffer (Promega). Luciferase activity was measured using the Luciferase Assay System (Promega). $\beta$-Galactosidase activity was assayed using the Galacto-Light Plus chemiluminescence assay (Tropix, Applied Biosystems). Luciferase levels in individual samples were normalized to $\beta$-galactosidase activity. 
ChIP assay. Two $15-\mathrm{cm}$ plates of approximately $80 \%$ confluent rat IMCD cells were cultured for 24 hours. $\mathrm{NaCl}(75 \mathrm{mM})$ or sucrose $(150 \mathrm{mM})$ treatment in DMEM culture medium was performed for 4 hours. Cells (two $15-\mathrm{cm}$ plates per experimental condition) were then crosslinked with $1 \%$ formaldehyde (final concentration) for 10 minutes at room temperature. The reaction was stopped by addition of glycine to a final concentration of $0.125 \mathrm{M}$ for 5 minutes at room temperature. Cells were washed with cold PBS and scraped into 50-ml tubes. Cells were lysed in $10 \mathrm{ml}$ cell lysis buffer (5 mM PIPES, pH 8.0, 85 mM KCl, 0.5\% NP-40, and protease inhibitor cocktail) for 10 minutes on ice. Released nuclei were lysed in $2 \mathrm{ml}$ nuclear lysis buffer (50 mM Tris-HCl, pH 8.1, 10 mM EDTA, 1\% SDS, and protease inhibitor cocktail) for another 10 minutes on ice. Nuclear lysates were sonicated to a final average fragment length of $1 \mathrm{~kb}$. Sonicated chromatin was cleared by centrifugation at $20,800 \mathrm{~g} 4^{\circ} \mathrm{C}$ for 10 minutes. Two hundred micrograms of sheared chromatin was used for each immunoprecipitation. Chromatin was first precleared with $100 \mu \mathrm{lBSA}$ - and salmon sperm DNAblocked Protein A Sepharose (GE Healthcare) beads for 1 hour at $4^{\circ} \mathrm{C}$. Two micrograms of normal rabbit serum or specific antibody (see Figure 5) was added to each $100 \mu \mathrm{g}$ of precleared chromatin and incubated overnight on a rotating platform at $4{ }^{\circ} \mathrm{C}$. The following morning, another $100 \mu \mathrm{l}$ of beads was added to collect precipitated complexes. Beads were sequentially washed in 4 different buffers: TSE I buffer $(0.1 \%$ SDS, $1 \%$ Triton X-100, 2 mM EDTA, 20 mM Tris-HCl, pH 8.1, 150 mM NaCl), TSE II buffer (same as TSE I with addition of $500 \mathrm{mM} \mathrm{NaCl})$, ChIP buffer III $(0.25 \mathrm{mM} \mathrm{LiCl}$, $1 \%$ NP-40, 1\% deoxycholate, $1 \mathrm{mM}$ EDTA, $10 \mathrm{mM}$ Tris-HCl, $\mathrm{pH} 8.1$ ), and TE buffer (1 mM EDTA, 10 mM Tris-HCl, pH 8.1). Precipitated complexes were eluted twice from the beads in fresh elution buffer (1\% SDS, $0.1 \mathrm{M}$ $\mathrm{NaHCO}_{3}$ ) for 30 minutes each at room temperature. Crosslinking was reversed overnight at $65-67^{\circ} \mathrm{C}$. The next morning, samples were precipitated with $\mathrm{NaCl}$ and ethanol (100\%). Pellets were resuspended in $100 \mu \mathrm{lTE}$ buffer. Two microliters of high-concentration RNase A (1579681; Roche) was added, and the sample was incubated for 2 hours at $37^{\circ} \mathrm{C}$. At that point, $25 \mu \mathrm{l} 5 \times$ PK buffer (50 mM Tris-HCl, pH 7.5, 25 mM EDTA, 1.25\% SDS, and $1.5 \mu \mathrm{l}$ proteinase $\mathrm{K}[25 \mathrm{mg} / \mathrm{ml}]$ ) was added, and the incubation was continued another 2 hours at $55^{\circ} \mathrm{C}$. Samples were extracted with phenol:chloroform:isoamylalcohol, followed by chloroform:isoamylalcohol. DNA was precipitated and quantified by NanoDrop (Thermo Scientific). Ten nanograms of precipitated DNA were used per PCR reaction. Primer locations are shown in Figure 5; their sequences are provided below. PCR was carried out under standard conditions with annealing temperature of $58^{\circ} \mathrm{C}$ for 32 cycles.

To study the interaction of protein binding with exogenous (i.e., transiently transfected) rat $S g k 1$ gene promoter sequence, IMCD cells were transfected with $20 \mu \mathrm{g}-1,430$ Sgk1-Luc or -1,430 M3-Sgk1-Luc, cultured for 44 hours, and treated with sucrose $(150 \mathrm{mM})$ or $\mathrm{NaCl}(75 \mathrm{mM})$ in DMEM for 4 hours prior to collection, chromatin preparation, and analysis (as described above).

Four primers were used to amplify TonE and non-TonE-containing fragments in the endogenous rat Sgk1 promoter (primer 1: 5'-GAGATCAGGGCGGAGTACAG-3', primer 2: 5'-AGAACCGAGGCTTCCACAG-3', primer 3: 5'-ACCGTCATCTTTCAGCGTTT-3' ${ }^{\prime}$, primer 4: $5^{\prime}$-TTGCCCTGGAGCTTTAATGT- $3^{\prime}$ ) (see Figure 5 for the position of these primers). The TonE fragment in the transfected Sgk1 promoter sequence was obtained by using primers 1 and 5 (see Figure 5). The latter is an antisense primer in the luciferase gene coding sequence (primer 5: 5'-CTTCCAGCGGATAGAATGGC-3').

In vivo dehydration studies. Adult male Sprague-Dawley rats, weighing approximately $250 \mathrm{~g}$, were used in this study. Before water restriction, the rats were weighed and transferred to clean metabolic cages. A control group of animals had free access to water and standard chow. The 24-hour water-restricted group was provided only with chow. Urine was collected during the last 15 hours. An aliquot from the final 15-hour urine sample was used to measure osmolality and sodium. On completion of 24-hour water deprivation, animals were anesthetized by intraperitoneal injection of Inactin (Sigma-Aldrich) $(100 \mathrm{mg} / \mathrm{kg})$ and weighed. Blood pressure was measured by insertion of a tapered polyethylene catheter into the carotid artery. The catheter was connected to a Statham blood pressure transducer attached to a direct writing recorder. Blood was collected in ice-cold tubes containing $\mathrm{Na}_{2}$ EDTA and aprotinin. Plasma was prepared for immediate measurement of osmolality and sodium and stored at $-70^{\circ} \mathrm{C}$ for later measurements of aldosterone using an EIA kit (Cayman Chemical) and ANP using an ANP RIA kit (Phoenix Pharmaceuticals Inc.). Urine was collected for the final 2 hours for measurement of volume, sodium, cyclic GMP (cyclic GMP RIA kit; PerkinElmer), and immunoreactive urodilatin (urodilatin RIA kit; Phoenix Pharmaceuticals Inc.). More than 99\% of natriuretic peptide immunoreactivity in the urine reflects urodilatin (66). The inner medullas of paired kidneys were isolated for the measurements of Sgk1, NPR-A, urodilatin, $\alpha \mathrm{ENaC}, \beta$-tubulin, and GAPDH mRNAs and/or proteins. Urine and plasma sodium were measured by flame photometry (model 943; Instrumentation Laboratory). Urine and plasma osmolalities were determined by osmometry (Advanced Instruments).

Npr1 $1^{-1-}$ mice were purchased from The Jackson Laboratory (stock 004374). Mouse blood pressure was measured using the tail-cuff method. Mice were trained on the Hatteras Instruments SC1000 Blood Pressure Analysis System according to manufacturer's instructions for 4 days. Ten consecutive measurements on the last day were averaged to calculate systolic and diastolic blood pressure. Adult wild-type and $\mathrm{Npr1}^{-/-}$mice were subjected to 24-hour water deprivation, while their respective control mice had free access to water. Urine was collected during the last 15 hours. An aliquot from the final 15-hour urine sample was used to measure osmolality, sodium, and cGMP concentration. Renal inner medullas were isolated for measurement of NPR-A and Sgk1 protein expression.

RNA isolation and real-time PCR analysis. Total RNA from isolated renal inner medullas, atria, and IMCD cells were prepared using the RNeasy Mini Kit (QIAGEN). Six hundred nanograms of total RNA were reverse transcribed into cDNA using Superscript III reverse transcriptase (Invitrogen). Real-time PCR was performed with rat ANP (catalog Rn00561661_ml) and GAPDH (catalog Rn99999916_sl) Taqman primers (Applied Biosystems) and rat Sgk1 (sense: CAAGGAGAACATCGAGCACA; antisense: TTTCAGCTGGAGAGGCTTGT), NPR-A (sense: GGAGAAGCCCTCAAGATCCACT; antisense: CTTGCCTTTGCCCTTCATTTC), and GAPDH (sense: GACATGCCGCCTGGAGAAAC; antisense: AGCCCAGGATGCCCTTTAGT) SYBR Green (Applied Biosystems) primers. ANP, sgk1, and NPR-A transcript levels were quantified and normalized to GAPDH transcript levels in each sample. The thermal cycles of the ABI Prism 7900 Sequence Detection System (Applied Biosystems) were $50^{\circ} \mathrm{C}$ for 2 minutes, $95^{\circ} \mathrm{C}$ for 10 minutes, for Taqman activation, followed by 40 cycles of $95^{\circ} \mathrm{C}$ for 15 seconds and $60^{\circ} \mathrm{C}$ for 60 seconds.

Immunoblotting. The isolated renal inner medulla from rats and mice was immediately homogenized in lysis buffer $(50 \mathrm{mM}$ Tris- $\mathrm{HCl}, \mathrm{pH} 7.5 ; 150$ $\mathrm{mM} \mathrm{NaCl}, 1 \%$ Triton X-100, 5 mM EDTA, 10\% glycerol, $1 \mathrm{mM}$ sodium orthovanadate, $10 \mathrm{mM}$ sodium fluoride, $1 \mathrm{mM}$ glycerophosphate) containing protease inhibitors (1 Complete tablet $/ 50 \mathrm{ml}$ ). For cultured IMCD cells, cells were collected, pelleted, and then lysed with the same lysis buffer. Forty micrograms of total protein was denatured at $100^{\circ} \mathrm{C}$ for $5 \mathrm{~min}$ utes, subjected to $9 \%$ SDS-PAGE, and transferred onto Immun-Blot PVDF membranes (Bio-Rad). Membranes were blocked with $5 \%$ nonfat milk in TBST (50 mM Tris-HCl, pH 7.5; $150 \mathrm{mM} \mathrm{NaCl}$, 0.1\% Tween-20) and probed with a mouse monoclonal antibody directed against Sgk1 (sc-28338; Santa Cruz Biotechnology Inc.) or a goat polyclonal IgG directed against $\alpha \mathrm{ENaC}$ (sc-22239; Santa Cruz Biotechnology Inc.). An HRP-conjugated second- 
ary antibody was used to detect immunoreactive bands using the ECL Western blotting detection system (Amersham, GE Healthcare). The same membranes were reblotted with anti-GAPDH antibody (sc-32233; Santa Cruz Biotechnology Inc.). Sgk1 and $\alpha \mathrm{ENaC}$ signals were quantified using a Kodak Scientific Imaging system and normalized to the GAPDH signal.

For preparation of the membrane fraction, IMCD cells were treated with $75 \mathrm{mM} \mathrm{NaCl}$ for 24 hours and then scraped into ice-cold PBS. After brief centrifugation, cells were resuspended in buffer A ( $20 \mathrm{mM}$ Tris, $\mathrm{pH} 7.5$, $10 \mathrm{mM}$ mannitol, and protease inhibitors) and homogenized. Isolated renal inner medullary tissue from rats or mice was homogenized in buffer A as described above. After centrifugation at $800 \mathrm{~g}$ for 10 minutes, soluble and membrane fractions from either cultured cells or medullary tissue were separated by centrifugation at $150,000 \mathrm{~g}$ for 1 hour at $4^{\circ} \mathrm{C}$. The particulate fractions were resuspended in the lysis buffer described above containing $2 \%$ Triton X-100. Forty micrograms of membrane protein was heated at $37^{\circ} \mathrm{C}$ for 15 minutes for Western blotting and probed with NPR-A antibody (PGCA-101AP; FabGennix Inc.). Chemiluminescence detection of rat and mouse NPR-A employed ECL and SuperSignal West Femto (Pierce Protein Research Products, Thermo Scientific), respectively. The same membrane was washed and reprobed with $\beta$-tubulin antibody (sc-9104; Santa Cruz Biotechnology Inc.). NPR-A signal was quantified using a Kodak Scientific Imaging system and normalized to the $\beta$-tubulin signal.

siRNA silencing of Sgk1 and NPR-A genes. Twenty-one nucleotide-annealed duplex siRNAs directed against rat Sgk1 gene sequence (siSgk1A, GGAGCCCGAACUUAUGAACtt; siSgk1B, CCAUCAUUUUAAUGUCCUGtt; and siSgk1C GGUUCUUCUAGCAAGGCACtt - all sense strand) were chemically synthesized and purified using a commercial source (Ambion, Applied Biosystems), as was a negative control siRNA (Ambion, Applied Biosystems) containing a 19-bp scrambled sequence. The latter sequences have no significant homology to any known gene sequences from the rat genome. IMCD cells were cultured to $60 \%-70 \%$ confluence and then transfected with $100 \mathrm{pmol}$ siSgk1A, siSgk1B, siSgk1C, or the negative control siRNA using Oligofectamine (Invitrogen) according to the manufacturer's instructions. Forty-eight hours after transfection, cells were washed, and cellular lysates were prepared and analyzed for Sgk1 and NPR-A mRNAs and proteins by real-time PCR and Western blot analysis.

Statistics. Data were analyzed by 1 -way ANOVA using the NewmanKeuls test to assess statistical differences between multiple groups. Onetailed Student's $t$ test was used for comparisons between 2 groups. All data are presented as mean $\pm \mathrm{SD}$. A $P$ value less than 0.05 was considered statistically significant.

\section{Acknowledgments}

Antibody directed against NFAT5 for pilot experiments was generously provided by H. Moo Kwon. U6 ShRNAi-NFAT5 and NFAT5DN were gifts from Anne Goldfeld. We are grateful for the rat Sgk1CAT reporter provided by Gary Firestone. We are grateful to D. Pearce for critical reading of the manuscript and D. Glenn for technical advice on the ChIP analyses. This work was supported by NIH grants HL45637 (to D.G. Gardner) and HL68871 (to M.H. Humphreys).

Received for publication February 12, 2008, and accepted in revised form March 18, 2009.

Address correspondence to: Songcang Chen, Diabetes Center, 1119 HSW, UCSF, San Francisco, California 94143-0540, USA. Phone: (415) 476-2729; Fax: (415) 564-5813; E-mail: schen@ diabetes.ucsf.edu.
1. Andersen, L.J., Andersen, J.L., Pump, B., and Bie, P. 2002. Natriuresis induced by mild hypernatremia in humans. Am. J. Physiol. Regul. Integr. Comp. Physiol. 282:R1754-R1761.

2. Huang, W., Lee, S.L., Arnason, S.S., and Sjoquist, M. 1996. Dehydration natriuresis in male rats is mediated by oxytocin. Am. J. Physiol. 270:R427-R433.

3. Lucke, C., Erbler, H., Herting, T., and Dohler, K.D. 1980. Secretion of arginin-vasopressin, aldosterone and corticosterone and plasma-renin activity in water-deprived rats. Contrib. Nephrol. 19:63-70.

4. Luke, R.G. 1973. Natriuresis and chloruresis during hydrogenia in the rat. Am. J. Physiol. 224:13-20.

5. McKenna, T.M., and Haines, H. 1981. Sodium metabolism during acclimation to water restriction by wild mice, Mus musculus. Am. J. Physiol. 240:R319-R326.

6. McKinley, M.J., Denton, D.A., Nelson, J.F., and Weisinger, R.S. 1983. Dehydration induces sodium depletion in rats, rabbits, and sheep. Am. J. Physiol. 245:R287-R292.

7. McKinley, M.J., Evered, M.D., and Mathai, M.L. 2000. Renal Na excretion in dehydrated and rehydrated adrenalectomized sheep maintained with aldosterone. Am. J. Physiol. Regul. Integr. Comp. Physiol. 279:R17-R24.

8. Merrill, D.C., Skelton, M.M., and Cowley, A.W., Jr. 1986. Humoral control of water and electrolyte excretion during water restriction. Kidney Int. 29:1152-1161.

9. Metzler, G.H., Thrasher, T.N., Keil, L.C., and Ramsay, D.J. 1986. Endocrine mechanisms regulating sodium excretion during water deprivation in dogs. Am. J. Physiol. 251:R560-R568.

10. Thrasher, T.N., Wade, C.E., Keil, L.C., and Ramsay, D.J. 1984. Sodium balance and aldosterone during dehydration and rehydration in the dog. Am.J. Physiol. 247:R76-R83.

11. Zucker, A., Gleason, S.D., and Schneider, E.G. 1982. Renal and endocrine response to water deprivation in dog. Am.J. Physiol. 242:R296-R302.

12. Huang, W., Lee, S.L., and Sjoquist, M. 1995. Natriuretic role of endogenous oxytocin in male rats infused with hypertonic NaCl. Am. J. Physiol. 268:R634-R640.

13. Ko, B.C., Ruepp, B., Bohren, K.M., Gabbay, K.H., and Chung, S.S. 1997. Identification and characterization of multiple osmotic response sequences in the human aldose reductase gene. J. Biol. Chem. 272:16431-16437.

14. Miyakawa, H., et al. 1998. Cis- and trans-acting factors regulating transcription of the BGT1 gene in response to hypertonicity. Am. J. Physiol. 274:F753-F761.

15. Ito, T., et al. 2004. Expression of taurine transporter is regulated through the TonE (tonicity-responsive element)/TonEBP (TonE-binding protein) pathway and contributes to cytoprotection in HepG2 cells. Biochem. J. 382:177-182.

16. Woo, S.K., Lee, S.D., Na, K.Y., Park, W.K., and Kwon, H.M. 2002. TonEBP/NFAT5 stimulates transcription of HSP70 in response to hypertonicity. Mol. Cell. Biol. 22:5753-5760.

17. Rim, J.S., et al. 1998. Transcription of the sodium/ myo-inositol cotransporter gene is regulated by multiple tonicity-responsive enhancers spread over 50 kilobase pairs in the $5^{\prime}$-flanking region. J. Biol. Chem. 273:20615-20621.

18. Nakayama, Y., Peng, T., Sands, J.M., and Bagnasco, S.M. 2000. The TonE/TonEBP pathway mediates tonicity-responsive regulation of UT-A urea transporter expression. J. Biol. Chem. 275:38275-38280.

19. Hasler, U., et al. 2006. Tonicity-responsive enhancer binding protein is an essential regulator of aquaporin-2 expression in renal collecting duct principal cells. J. Am. Soc. Nephrol. 17:1521-1531.

20. Miyakawa, H., Woo, S.K., Dahl, S.C., Handler, J.S., and Kwon, H.M. 1999. Tonicity-responsive enhancer binding protein, a rel-like protein that stimulates transcription in response to hypertonicity. Proc. Natl. Acad. Sci. U. S. A. 96:2538-2542.
21. Stroud, J.C., Lopez-Rodriguez, C., Rao, A., and Chen, L. 2002. Structure of a TonEBP-DNA complex reveals DNA encircled by a transcription factor. Nat. Struct. Biol. 9:90-94.

22. Lee, S.D., Woo, S.K., and Kwon, H.M. 2002. Dimerization is required for phosphorylation and DNA binding of TonEBP/NFAT5. Biochem. Biophys. Res. Commun. 294:968-975.

23. Lopez-Rodriguez, C., Aramburu, J., Rakeman, A.S. and Rao, A. 1999. NFAT5, a constitutively nuclear NFAT protein that does not cooperate with Fos and Jun. Proc. Natl. Acad. Sci. U. S. A. 96:7214-7219.

24. Dahl, S.C., Handler, J.S., and Kwon, H.M. 2001. Hypertonicity-induced phosphorylation and nuclear localization of the transcription factor TonEBP. Am. J. Physiol. Cell Physiol. 280:C248-C253.

25. Zhang, Z., et al. 2005. Ataxia telangiectasia-mutated, a DNA damage-inducible kinase, contributes to high $\mathrm{NaCl}$-induced nuclear localization of transcription factor TonEBP/OREBP. Am. J. Physiol. Renal Physiol. 289:F506-F511.

26. Cha, J.H., et al. 2001. Hydration status affects nuclear distribution of transcription factor tonicity responsive enhancer binding protein in rat kidney. J. Am. Soc. Nephrol. 12:2221-2230.

27. Cai, Q., Ferraris, J.D., and Burg, M.B. 2005. High $\mathrm{NaCl}$ increases TonEBP/OREBP mRNA and protein by stabilizing its mRNA. Am. J. Physiol. Renal Physiol. 289:F803-F807.

28. Woo, S.K., Dahl, S.C., Handler, J.S., and Kwon, H.M. 2000. Bidirectional regulation of tonicityresponsive enhancer binding protein in response to changes in tonicity. Am. J. Physiol. Renal Physiol. 278:F1006-F1012.

29. Webster, M.K., Goya, L., Ge, Y., Maiyar, A.C., and Firestone, G.L. 1993. Characterization of sgk, a novel member of the serine/threonine protein kinase gene family which is transcriptionally induced by glucocorticoids and serum. Mol. Cell. Biol. 13:2031-2040. 
30. Leong, M.L., Maiyar, A.C., Kim, B., O’Keeffe, B.A., and Firestone, G.L. 2003. Expression of the serumand glucocorticoid-inducible protein kinase, Sgk, is a cell survival response to multiple types of environmental stress stimuli in mammary epithelial cells. J. Biol. Chem. 278:5871-5882.

31. Lang, F., et al. 2000. Deranged transcriptional regulation of cell-volume-sensitive kinase hSGK in diabetic nephropathy. Proc. Natl. Acad. Sci. U. S. A. 97:8157-8162.

32. Waldegger, S., et al. 1999. h-sgk serine-threonine protein kinase gene as transcriptional target of transforming growth factor beta in human intestine. Gastroenterology. 116:1081-1088.

33. Chen, S.Y., et al. 1999. Epithelial sodium channel regulated by aldosterone-induced protein sgk. Proc. Natl. Acad. Sci. U. S. A. 96:2514-2519.

34. Bell, L.M., et al. 2000. Hyperosmotic stress stimulates promoter activity and regulates cellular utilization of the serum- and glucocorticoid-inducible protein kinase (Sgk) by a p38 MAPK-dependent pathway. J. Biol. Chem. 275:25262-25272.

35. Klingel, K., et al. 2000. Expression of cell volumeregulated kinase h-sgk in pancreatic tissue. Am.J. Physiol. Gastrointest. Liver Physiol. 279:G998-G1002.

36. Waldegger, S., Barth, P., Forrest, J.N., Jr., Greger, R., and Lang, F. 1998. Cloning of sgk serine-threonine protein kinase from shark rectal gland - a gene induced by hypertonicity and secretagogues. Pflugers Arch. 436:575-580.

37. Waldegger, S., Barth, P., Raber, G., and Lang, F. 1997. Cloning and characterization of a putative human serine/threonine protein kinase transcriptionally modified during anisotonic and isotonic alterations of cell volume. Proc. Natl. Acad. Sci.U. S. A. 94:4440-4445.

38. Waldegger, S., Gabrysch, S., Barth, P., Fillon, S., and Lang, F. 2000. h-sgk serine-threonine protein kinase as transcriptional target of p38/MAP kinase pathway in HepG2 human hepatoma cells. Cell. Physiol. Biochem. 10:203-208.

39. Uawithya, P., Pisitkun, T., Ruttenberg, B.E., and Knepper, M.A. 2008. Transcriptional profiling of native inner medullary collecting duct cells from rat kidney. Physiol. Genomics. 32:229-253.

40. Chen, S., et al. 2004. Sgk1 mediates osmotic induction of NPR-A gene in rat inner medullary collecting duct cells. Hypertension. 43:866-871.

41. Chen, S., and Gardner, D.G. 2002. Osmoregulation of natriuretic peptide receptor signaling in inner medullary collecting duct. A requirement for p38 MAPK. J. Biol. Chem. 277:6037-6043.

42. Cowley, B.D., Jr., Ferraris, J.D., Carper, D., and Burg, M.B. 1990. In vivo osmoregulation of aldose reductase mRNA, protein, and sorbitol in renal medulla. Am. J. Physiol. 258:F154-F161.

43. Yamauchi, A., et al. 1994. In vivo osmoregulation of $\mathrm{Na}$ /myo-inositol cotransporter mRNA in rat kidney medulla. J. Am. Soc. Nephrol. 5:62-67.

44. Ferraris, J.D., Williams, C.K., Ohtaka, A., and Garcia-Perez, A. 1999. Functional consensus for mammalian osmotic response elements. Am. J. Physiol. 276:C667-C673.

45. Daoudal, S., Tournaire, C., Halere, A., Veyssiere, G., and Jean, C. 1997. Isolation of the mouse aldose reductase promoter and identification of a tonicityresponsive element. J. Biol. Chem. 272:2615-2619.

46. Esensten, J.H., et al. 2005. NFAT5 binds to the TNF promoter distinctly from NFATp, c, 3 and 4 , and activates TNF transcription during hypertonic stress alone. Nucleic Acids Res. 33:3845-3854.

47. Rozansky, D.J., et al. 2002. Hypotonic induction of SGK1 and $\mathrm{Na}^{+}$transport in A6 cells. Am. J. Physiol. Renal Physiol. 283:F105-F113.

48. Hills, C.E., Bland, R., Bennett, J., Ronco, P.M., and Squires, P.E. 2006. High glucose up-regulates $\mathrm{ENaC}$ and SGK1 expression in HCD-cells. Cell. Physiol. Biochem. 18:337-346.

49. Vasquez, M.M., et al. 2008. Induction of serum- and glucocorticoid-induced kinase-1 (SGK1) by cAMP regulates increases in alpha-ENaC. J. Cell. Physiol. 217:632-642.

50. Forssmann, W.G., Richter, R., and Meyer, M. 1998. The endocrine heart and natriuretic peptides: histochemistry, cell biology, and functional aspects of the renal urodilatin system. Histochem. Cell Biol. 110:335-357.

51. Schulz-Knappe, P., et al. 1988. Isolation and structural analysis of "urodilatin", a new peptide of the cardiodilatin-(ANP)-family, extracted from human urine. Klin. Wochenschr. 66:752-759.

52. Forssmann, W., Meyer, M., and Forssmann, K. 2001. The renal urodilatin system: clinical implications. Cardiovasc. Res. 51:450-462.

53. Lopez, M.J., et al. 1995. Salt-resistant hypertension in mice lacking the guanylyl cyclase-A receptor for atrial natriuretic peptide. Nature. 378:65-68.

54. Tong, E.H., et al. 2006. Regulation of nucleocyto- plasmic trafficking of transcription factor OREBP/ TonEBP/NFAT5. J. Biol. Chem. 281:23870-23879.

55. Burg, M.B., Kwon, E.D., and Kultz, D. 1997. Regulation of gene expression by hypertonicity. Annu. Rev. Physiol. 59:437-455.

56. Jeon, U.S., Kim, J.A., Sheen, M.R., and Kwon, H.M. 2006. How tonicity regulates genes: story of TonEBP transcriptional activator. Acta Physiol. (Oxf.). 187:241-247.

57. Rasmussen, M.S., Simonsen, J.A., Sandgaard, N.C., Hoilund-Carlsen, P.F., and Bie, P. 2004. Effects of oxytocin in normal man during low and high sodium diets. Acta Physiol. Scand. 181:247-257.

58. Rubera, I., et al. 2003. Collecting duct-specific gene inactivation of $\alpha \mathrm{ENaC}$ in the mouse kidney does not impair sodium and potassium balance. J. Clin. Invest. 112:554-565.

59. Sonnenberg, H., Honrath, U., and Wilson, D.R. 1990. In vivo microperfusion of inner medullary collecting duct in rats: effect of amiloride and ANF. Am. J. Physiol. 259:F222-F226.

60. Light, D.B., Schwiebert, E.M., Karlson, K.H., and Stanton, B.A. 1989. Atrial natriuretic peptide inhibits a cation channel in renal inner medullary collecting duct cells. Science. 243:383-385.

61. Sonnenberg, H., Honrath, U., Chong, C.K., and Wilson, D.R. 1986. Atrial natriuretic factor inhibits sodium transport in medullary collecting duct. Am. J. Physiol. 250:F963-F966.

62. Palmer, B.F. 2003. Hyponatremia in patients with central nervous system disease: SIADH versus CSW. Trends Endocrinol. Metab. 14:182-187.

63. Baylis, P.H. 2003. The syndrome of inappropriate antidiuretic hormone secretion. Int. J. Biochem. Cell Biol. 35:1495-1499.

64. Grenier, F.C., Rollins, T.E., and Smith, W.L. 1981. Kinin-induced prostaglandin synthesis by renal papillary collecting tubule cells in culture. Am. J. Physiol. 241:F94-F104.

65. Chen, S., Cao, L., Intengan, H.D., Humphreys, M., and Gardner, D.G. 2002. Osmoregulation of endothelial nitric-oxide synthase gene expression in inner medullary collecting duct cells. Role in activation of the type A natriuretic peptide receptor. J. Biol. Chem. 277:32498-32504.

66. Lee, Y.J., Shin, S.J., Tan, M.S., Hsieh, T.J., and Tsai, J.H. 1996. Increased renal atrial natriuretic peptide synthesis in rats with deoxycorticosterone acetatesalt treatment. Am. J. Physiol. 271:F779-F789. 